\title{
Non-suckling starvation of neonatal mice promotes primordial follicle formation with activation of ovarian autophagy
}

\author{
Ren WATANABE ${ }^{1-3)}$ and Naoko KIMURA ${ }^{1,2)}$ \\ 1) Laboratory of Animal Reproduction, United Graduate School of Agricultural Sciences, Iwate University, \\ Tsuruoka 997-8555, Japan \\ 2) Laboratory of Animal Reproduction, Graduate School of Agricultural Science, Yamagata University, Tsuruoka 997-8555, \\ Japan \\ 3) Japan Society for the Promotion of Science (JSPS) Research Fellowships for Young Scientists, Tokyo, Japan
}

\begin{abstract}
Around the time of oocyte meiotic arrest, germ cell nest breakdown occurs, and primordial follicle (PF) formation is initiated at the perinatal stage. Recently, autophagy was implicated in this process. Autophagy is induced by nutrient starvation. This study was conducted to understand how starvation affects PF formation and autophagy induction during neonatal life. Suckling of neonatal female mice was blocked immediately after birth for 12-36 h to induce starvation. The numbers of PFs at each stage were subsequently counted from serial sections of ovaries. The expression of autophagyrelated proteins was also evaluated. The number of PFs peaked at $60 \mathrm{~h}$ after birth in the control group. The numbers for the starvation groups were significantly higher than those for the control groups at 12 and $36 \mathrm{~h}$. LC 3B was clearly present in the oocyte cytoplasm. At $36 \mathrm{~h}$ after birth, the starvation group showed a higher rate of LC3II/LC3-I expression as a marker for autophagy. Moreover, the expression of p62 as a selective substrate for autophagy decreased compared to the control group. The expression of caspase- 9 as a marker for apoptosis tended to be lower at $36 \mathrm{~h}$ in the starvation groups. These results indicate that starvation promotes PF formation with a concomitant activation of autophagy in early neonatal ovaries, suggesting that autophagy induction during follicle assembly might increase the number of PFs.
\end{abstract}

Key words: Autophagy, Mice, Neonatal, Primordial follicles, Starvation

(J. Reprod. Dev. 64: 89-94, 2018)

n mammals, primordial follicles (PFs) are established in the fetal or prenatal stages, depending on the species [1-3]. The processes associated with the formation and maintenance of PFs are not fully understood. Thus, a better understanding of these mechanisms would permit us to have an abundant source of female gametes for improving reproductive ability and lifespan in farm animals, humans, and endangered species. A primary question is how PF formation is regulated in the neonatal period. Around the time that the oogonia initiate meiosis and arrest at the diplotene stage of meiosis I, germ cell nests break down and PF formation is simultaneously initiated. Each oocyte becomes surrounded by somatic cells and forms a PF. In mice, it has been reported that follicle formation occurs immediately after birth [1].

During the transition from the fetal to the neonatal period, neonates face severe starvation during the period between loss of the transplacental nutrient supply and when they begin to suckle and are replenished with milk nutrients. Because of this, the organ system is adapted to postpartum starvation. Many organ systems in the neonatal stage adjust their cell density and function by multiple mechanisms

Received: September 15, 2017

Accepted: November 23, 2017

Published online in J-STAGE: December 21, 2017

(C)2018 by the Society for Reproduction and Development

Correspondence: Naoko Kimura (e-mail: naonao@tds1.tr.yamagata-u.ac.jp)

This is an open-access article distributed under the terms of the Creative Commons Attribution Non-Commercial No Derivatives (by-nc-nd) License. (CC-BY-NC-ND 4.0: https://creativecommons.org/licenses/by-nc-nd/4.0/) of programmed cell death [4]. Macroautophagy (autophagy), which is evolutionarily conserved from yeast to mammals [5], is one of the mechanisms promoting programmed cell death, and it is the primary intracellular catabolic mechanism for degrading and recycling long-lived proteins and organelles. During autophagy, phagophores enclose parts of the cytoplasm and intracellular organelles and form a double membrane structure, known as an autophagosome. At this time, a cytosolic form (LC3-I) of the microtubule-associated protein 1B-light chain 3 (LC3B) is conjugated to phosphatidylethanolamine to form LC3-phosphatidylethanolamine conjugate (LC3-II), which is recruited to autophagosomal membranes [6]. The autophagosome then fuses with the lysosome to form an autolysosome, the contents of which are then degraded by resident hydrolase enzymes [6]. In selective autophagy, p62, also known as sequestosome 1, is degraded as a substrate. When excessive activation of autophagy occurs, there is a possibility that this will lead to cell death such as the induction of apoptosis by the caspase family. It is known that autophagy is required for oogenesis in Drosophila ovaries [7].

Recent investigations have emphasized the relationship between PF formation and autophagy. A deficiency of the Atg7 or Becn 1 genes, which are essential for autophagy, results in an excessive loss of neonatal mouse ovarian PFs [8, 9]. In addition, LAMP-1, a marker for lysosomes involved in both autophagy and apoptosis, was highly expressed in PFs compared with other follicles at other stages [10]. These findings indicate that autophagy is likely involved in the transition from oocytes to PFs.

Autophagy is mainly induced in eukaryotic cells by nutrient 
starvation through the inhibition of the mammalian target of rapamycin (mTOR) protein, an evolutionarily conserved protein kinase. Autophagy is suppressed by the presence of excess amino acids. It is well known that mTOR signaling, together with protein kinase $\mathrm{B}$, acts to promote both $\mathrm{PF}$ activation and the growth of secondary follicles [11-13]. Several studies have reported on the effects of starvation (or calorie restriction) on female reproductive function. The collective findings indicate that calorie restriction may inhibit the activation of PFs as well as follicular development and loss, thus extending ovarian lifespan by suppressing mTOR and activating SIRT1 signaling in adult rats $[14,15]$.

In our preliminary studies, we found that lack of the cystine/ glutamate transporter (xCT), which regulates cysteine levels by limiting the uptake of cystine and also determines glutathione levels in cells, increases the number of PFs compared with wild type in 2-month-old mice (data not shown). Additionally, xCT deficiency induces autophagy [16]. Based on these findings, we hypothesized that autophagy activation during the perinatal stage would promote $\mathrm{PF}$ formation. In this study, we investigated the number of PFs and the autophagy mechanism in neonatal mouse ovaries under conditions of starvation, which is the major induction system for activating autophagy.

\section{Materials and Methods}

\section{Animals}

C57BL/6J mice were obtained from Charles River Japan and were mated to produce offspring. Newborns were separated from their mothers immediately after birth (within $6 \mathrm{~h}$ ) to induce starvation by blocking their nutrient supply from milk. The room that the mice were housed in was maintained under specific pathogen-free conditions at a constant temperature of $20-24^{\circ} \mathrm{C}$ with a $12 \mathrm{~h}$ alternating light-dark cycle. The neonatal survivors were sacrificed at 12,24 and $36 \mathrm{~h}$ after birth. One ovary obtained from each mouse was used to count PFs, and the other ovary was used for immunofluorescence staining or western blotting. Animal experiments were performed in accordance with the Declaration of Helsinki under the protocol approved by the Animal Research Committee of Yamagata University.

\section{Ovary collection and preparation for serial sections}

To assess follicle numbers, ovaries were collected from both nonfasted and starved neonates that were birthed in at least two separate litters. Intact bursa-enclosed ovaries were fixed in either Bouin solution for 4-6 h at room temperature for follicle counts or in $2 \%$ paraformaldehyde (PFA; Sigma, St. Louis, MO, USA) overnight at $4^{\circ} \mathrm{C}$ for immunohistochemistry. Following fixation, the ovaries were transferred to a $70 \%$ ethanol solution and processed for paraffin embedding by standard protocols. Serial sections $(8-\mu \mathrm{m}$ thickness) were stained with hematoxylin and eosin (HE) to count follicle numbers.

\section{Histological counting of PFs}

The total numbers of PFs per ovary were counted from all HEstained serial sections. The PFs were counted if they contained an oocyte surrounded by a partial or complete layer of squamous granulosa cells [17] (Supplementary Fig. 1: online only). To avoid double counting, only follicles with a visible oocyte nucleus were counted. In addition, all follicles were counted without knowledge of the experimental group of the animal.

\section{Immunofluorescence staining}

Paraffin sections (5- $\mu \mathrm{m}$ thickness) from control and starvation groups were deparaffinized, rehydrated, and microwaved for $15 \mathrm{~min}$ in $10 \mathrm{mM}$ citrate buffer, pH 6.0, to retrieve antigenicity. Nonspecific binding was blocked by treatment with $5 \%$ goat serum (Cedarlane, Burlington, Canada) for $1 \mathrm{~h}$ at room temperature. The resulting sections were then incubated with primary antibodies overnight at $4^{\circ} \mathrm{C}$. Control sections were incubated in the absence of a primary antibody. Each antibody and their dilution rates are shown in Supplementary Table 1 (online only). FITC-conjugated secondary anti-rabbit antibodies were next applied for $1 \mathrm{~h}$, and each section was rinsed with PBS plus 3\% BSA. Propidium iodide (PI) was used to label the nuclei. Finally, the slides were examined under a confocal laser microscope (ZEISS LSM700 Laser Scanning Microscope; Carl Zeiss, Oberkochen, Germany). The images were obtained by LSM software ZEN2009 (Carl Zeiss) and examined as digital images.

\section{Western blot analysis}

The ovaries of each experimental group were individually homogenized in $2 \%$ SDS and $62.5 \mathrm{mM}$ Tris-HCl-based sampling buffer ( $\mathrm{pH}$ 6.8). The digested samples were then sonicated and centrifuged at $13,000 \mathrm{rpm}$ for $15 \mathrm{~min}$ at $4{ }^{\circ} \mathrm{C}$ to remove insoluble debris. The equivalent of one ovary ( $20 \mu \mathrm{l}$ of each sample) was resolved on an SDS-polyacrylamide gel, then electrophoretically transferred to a PVDF membrane (Merck Millipore, Darmstadt, Germany), using the semidry technique. After blocking for $1 \mathrm{~h}$ with $3 \%(\mathrm{w} / \mathrm{v})$ skim milk in $0.1 \%(\mathrm{v} / \mathrm{v})$ Tween-20-Tris-buffered saline (T-TBS), the membranes were incubated overnight at $4{ }^{\circ} \mathrm{C}$ with primary antibodies diluted in Can Get Signal ${ }^{\circledR}$ solution I (Toyobo, Osaka, Japan). Each antibody and their dilution rates are shown in Supplementary Table 1. After washing the blot membranes in T-TBS, the membranes were incubated with horseradish peroxidase-conjugated secondary antibodies diluted in Can Get Signal ${ }^{\circledR}$ solution II (Toyobo). The secondary antibody was detected by an ImmunoStar®LD (Wako, Osaka, Japan) kit and a CCD camera, and specific band intensities were digitally quantified. The membrane was then incubated for 15 $\mathrm{m}$ at $55^{\circ} \mathrm{C}$ in stripping buffer $(2 \%$ SDS, $100 \mathrm{mM} \beta$-mercaptoethanol, and $62.5 \mathrm{mM}$ Tris- $\mathrm{HCl}$ ) to remove the antibodies. Thereafter, the membrane was repeatedly blotted with another antibody and detected. An anti-GAPDH antibody (Sigma) was used to verify comparable protein density between the samples in each experiment. At least three independent experiments were performed using other samples for each experimental group. The level of protein expression was estimated based on the intensity of staining of each membrane band using an image analysis software (ImageJ 1.38u; Wayne Rasband National Institutes of Health, USA) program.

\section{Statistical analysis}

For counting PFs, 4 to 6 ovaries per experimental group were used. Western blot analyses were normalized with GAPDH for each experiment, and the results were reported as the relative mean \pm SEM with the control group of $12 \mathrm{~h}$ for each experiment defined as 
1. The differences between the control and starvation groups were analyzed by ANOVA, and differences were calculated by Tukey's test. The data were considered to be significant when the P-value was $<0.05(*)$.

\section{Results}

Ovarian PFs increased during the early neonatal stage up to 60 $h$ post birth

To clarify the key stage for PF formation after birth, we identified PFs by immunohistochemistry using mouse vasa homolog (MVH) antibody as a germ cell molecular marker in postnatal ovaries (Fig. 1A) [18]. MVH was strongly localized in the oocyte cytoplasm, and its signal tended to be detected along the rim of the ovary cortex. Sections of ovaries at $12 \mathrm{~h}$ to $108 \mathrm{~h}$ after birth were morphometrically analyzed for total PF numbers (Fig. 1B). In this study, at $12 \mathrm{~h} \mathrm{PF}$ formation was sparse, and there were few PFs $(1,086 \pm 296.3)$ compared to other time points ( $24 \mathrm{~h}: 1,943 \pm 833.2 ; 36 \mathrm{~h}: 2,473 \pm$ 686.3). The number of PFs continued to increase until a peak was reached at $60 \mathrm{~h}(6,191 \pm 1,105.7)$, after which the number of PFs at $84 \mathrm{~h}(4,058 \pm 833.0)$ was reduced, and these levels were maintained for up to $108 \mathrm{~h}(3,729 \pm 1,175.8)$. Primary follicles began to be observed after $60 \mathrm{~h}$. Therefore, the transition from oocytes to PFs likely primarily occurred in the period from $12 \mathrm{~h}$ to $60 \mathrm{~h}$. After 60 $\mathrm{h}$, the transition from PFs to primary follicles would have begun; therefore, the decrease in the number of PFs at $84 \mathrm{~h}$ would be due to the transition from PFs to primary follicles.

\section{Starvation during the early neonatal stage increased the number of ovarian PFs}

In order to clarify the effect of starvation on the formation of PFs, the number of PFs was counted after starvation. Based on preliminary tests, starvation was enforced for up to $36 \mathrm{~h}$, which is the limit of survival for neonatal mice. Starvation groups had a higher number of PFs than control groups at each time point (Fig. 1B). In particular, the number of PFs was significantly higher at $12 \mathrm{~h}$ and $36 \mathrm{~h}(12 \mathrm{~h}$ : starvation $1,555 \pm 374.0 \mathrm{vs}$. control 1,086 $\pm 296.3 ; 36 \mathrm{~h}$ : starvation $4,232 \pm 1,519.0 v s$. control $2,473 \pm 686.3, \mathrm{P}<0.05)$. These results suggest that starvation promotes the formation of PFs or perhaps represses atresia of oocytes.

\section{Starvation during the early neonatal stage induces autophagy in the ovary}

LC3B is a protein that is bound stably and specifically to the expanding autophagosome membrane. [19]. During expansion, LC3-I is processed to LC3-II, which allows the quantity of autophagosomes to be estimated by Western blot. The starvation group showed a substantially higher ratio of LC3-II/LC3-I than the control group at 36 $\mathrm{h}(\mathrm{P}<0.05$, Fig. 2A, 2D). LC3B was strongly localized in the oocyte cytoplasm in both control and starvation groups at $36 \mathrm{~h}$ (Fig. 2E).

The membranes of lysosomes are enriched in specific membrane proteins that are referred to as lysosomal associated membrane proteins (LAMPs). The increased expression of LAMPs is a hallmark of autophagy [20]. By Western blot using a LAMP-1 antibody, two bands were detected very close together (Fig. 3A). The two bands showed similar trends whether they were quantified separately or simultaneously (data not shown). Therefore, we adopted the values of the two bands quantified simultaneously for our analysis. LAMP-1 levels tended to increase with time after birth and were higher in starvation groups than in control groups at 24 and $36 \mathrm{~h}$ (Fig. 3A, B). High levels of LAMP-1 were also found in the oocyte cytoplasm (Fig. 3C).

p62 is selectively incorporated into autophagosomes through direct binding to LC3 where it is efficiently degraded by autophagy. Thus, since the total cellular expression levels of p62 inversely correlate with autophagic activity, p62 is used to monitor autophagy [21-23]. The level of expression of p62 decreased in the starvation group compared with the control group at $36 \mathrm{~h}(\mathrm{P}<0.05$, Fig. 4A, B). p62 was localized in the cytoplasm of oocytes (Fig. 4C).

\section{Starvation during the early neonatal stage may suppress apoptosis in the ovary}

It is well known that the caspase family of proteins are crucial mediators of apoptosis. Caspase-3 plays a key role in ovarian apoptosis. Multiple pathways for caspase-3 activation have been identified, some of which are dependent on the release of mitochondrial cytochrome c and caspase-9 function, while others are independent of these processes. Caspase- 9 levels were decreased in the starvation group compared to the control group at $36 \mathrm{~h}$ (Fig. 5A, B). Caspase-9 was localized in the cytoplasm of both oocytes and somatic cells (Fig. $5 \mathrm{C}$ ). However, caspase-3 was not detected in any of the experimental groups (data not shown).

\section{Discussion}

In this study, non-suckling starvation of early neonatal mice increased the number of PFs in the ovaries of neonates. Furthermore, our findings indicate that the increased number of PFs is not due to suppression of the transition to the primary follicle, since the increase in PFs occurred before the appearance of primary follicles.

In the perinatal period, neonates must use stored energy until they are able to gain nutrition through lactation. The importance of autophagy has been reported in the perinatal period in several studies. One autophagy function is to allow organisms or cells to survive starvation conditions by recycling cellular components. Autophagy is linked to energy homeostasis and the maintenance of tissue viability in tissues during neonatal development in mammals [24-26]. This mechanism is important since it allows cells to adapt their metabolism to starvation conditions caused by decreased amounts of intracellular or extracellular nutrients. In addition to providing nutrition and adaptation to stress, autophagy is involved in numerous other physiological processes, such as cell death, development, and tumor suppression [27-32]. An Atg5 and Atg7 knockout study showed that perinatal lethality (death within 1 day of birth) was associated with the loss of autophagy during this early starvation period [24, 33]. Therefore, autophagy is an essential mechanism for maintaining energy homeostasis in neonates.

A burst of autophagy is induced at birth and reaches a peak within $12 \mathrm{~h}$, returning to basal levels within 1-2 days after. Similarly, autophagic activity (measured by the fluorescence intensity of LC3) was reported to be induced in the neonatal ovary immediately after birth, reaching a maximum level 3-6 h after birth, then gradually 
(A)

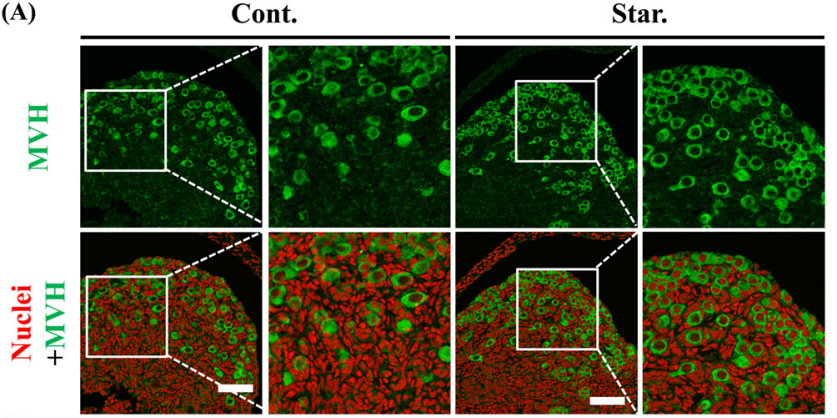

(B)

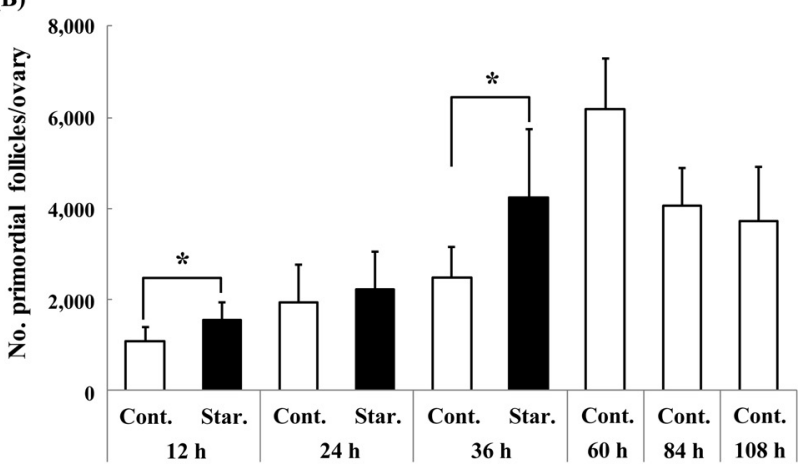

Fig. 1. (A) Fluorescent images from immunostaining of the PGCs (primordial germ cells) marker $\mathrm{MVH}$ in ovaries from control (Cont.) and starved (Star.) mice at 36 hours (h) after birth. Scale bars $=50 \mu \mathrm{m}$. The images on the right side of each experimental group are the quadruple enlargement of the white frame from images on the left. MVH was strongly localized in the oocyte cytoplasm, and its signals tended to be detected along the rim of the ovary cortex. (B) The numbers of PFs per ovary from control and starved mice at $12-108 \mathrm{~h}$ after birth. Data are expressed as the mean \pm SD $(n=4-6)$. Asterisks indicate significant differences $(\mathrm{P}<0.05)$. The number of PFs peaked at $60 \mathrm{~h}$. Starved groups showed a higher number of PFs than control groups at each time point.

(A)

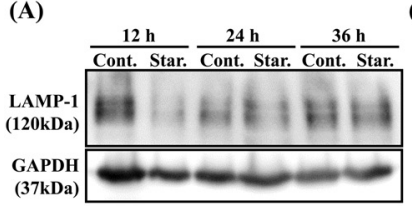

(B)

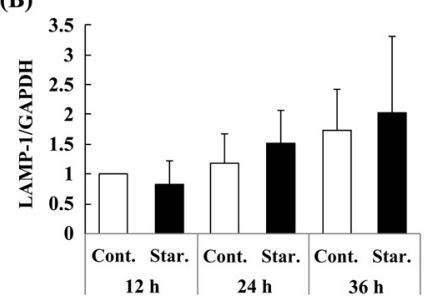

(C)
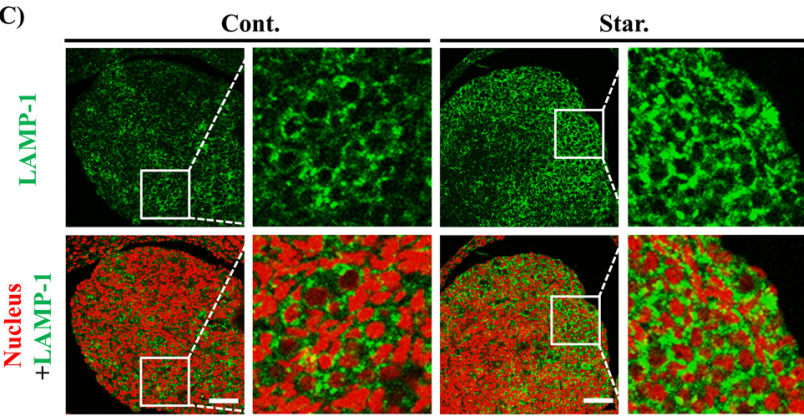

(A)

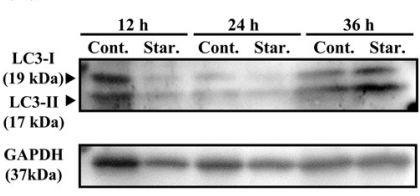

(B)

(C)

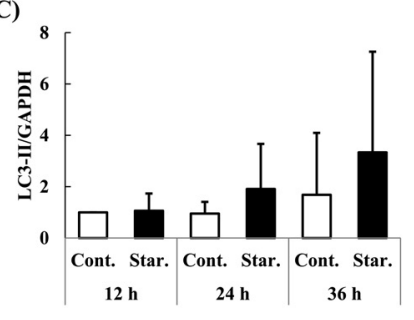

(E)
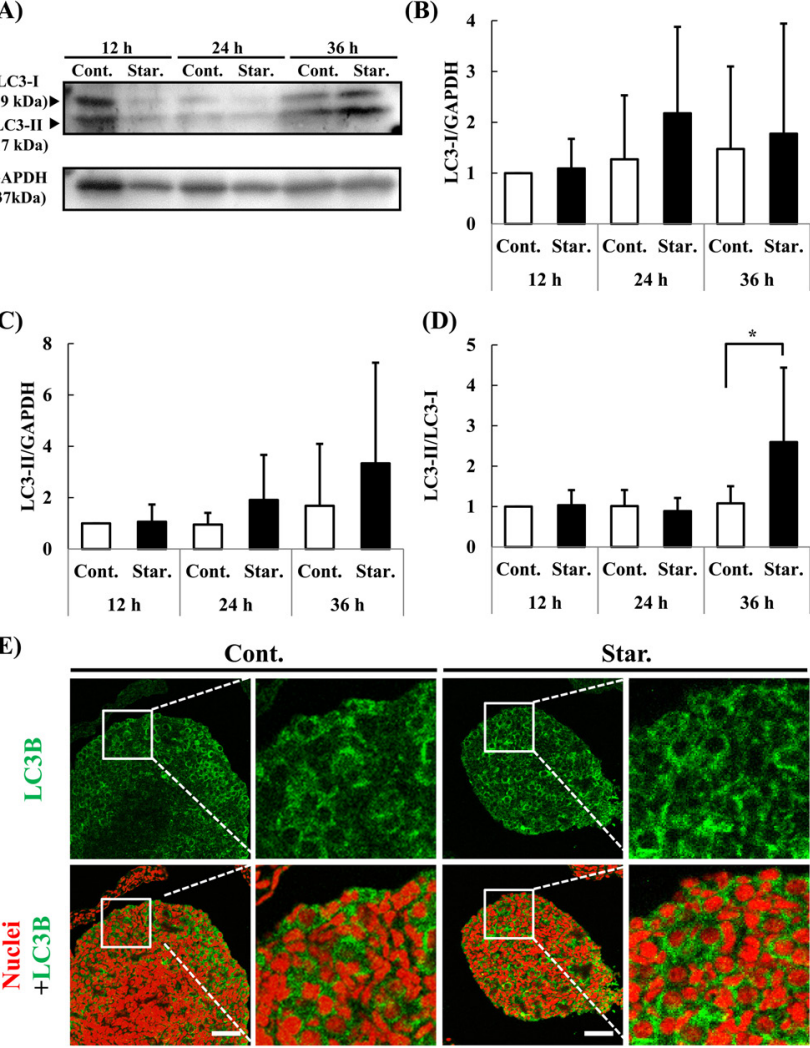

(D)
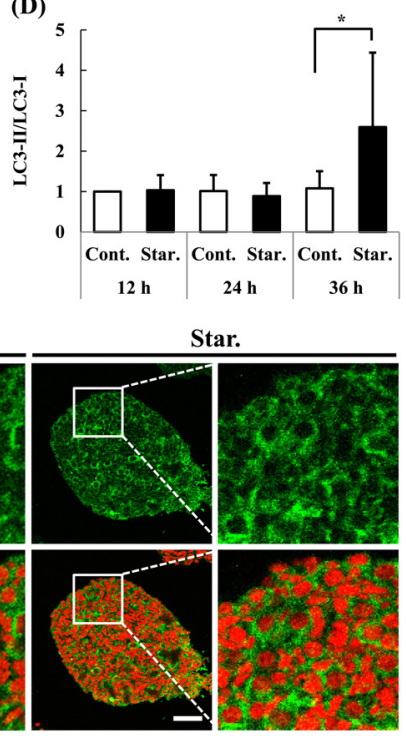

Fig. 2. (A) Protein expression of the autophagy marker LC3B in ovaries for control and starved groups at $12-36 \mathrm{~h}$ after birth. Relative expression levels of LC3-I (B) and II (C), and the LC3-II/I ratio (D) are shown in bar graphs. GAPDH was used as a loading control. Each bar is expressed as mean $\pm \mathrm{SE}(\mathrm{n}=9)$. An asterisk indicates a significant difference $(\mathrm{P}<0.05)$. Starved groups showed a higher ratio of LC3-II/LC3-I than the controls at 36 h. (E) Fluorescent images from immunostaining of the LC3B protein in ovaries for control and starved groups at $36 \mathrm{~h}$ after birth. Scale bar $=50 \mu \mathrm{m}$. The photographs on the right side of each experimental group are the quadruple enlargement of the white frame from images on the left. LC3B was localized highly in the oocyte cytoplasm.

Fig. 3. (A) Protein expression of the lysosomal marker LAMP-1 in ovaries from control and starved groups at $12-36 \mathrm{~h}$ after birth. (B) Relative expression levels of LAMP-1 are shown in bar graphs. GAPDH was used as a loading control. Each bar is expressed as the mean $\pm \mathrm{SE}(\mathrm{n}=7)$. An asterisk indicates a significant difference $(\mathrm{P}<0.05)$. LAMP-1 tended to increase with time after birth. (C) Fluorescent images from immunostaining of the LAMP-1 protein in ovaries from control and starved groups at $36 \mathrm{~h}$ after birth. Scale bar $=50 \mu \mathrm{m}$. The photographs on the right side of each experimental group are the quadruple enlargement of the white frame from images on the left. LAMP-1 was localized highly in the oocyte cytoplasm.

Fig. 3. 

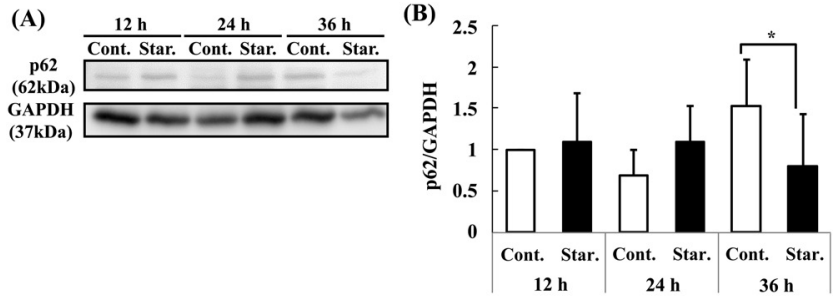

(C)
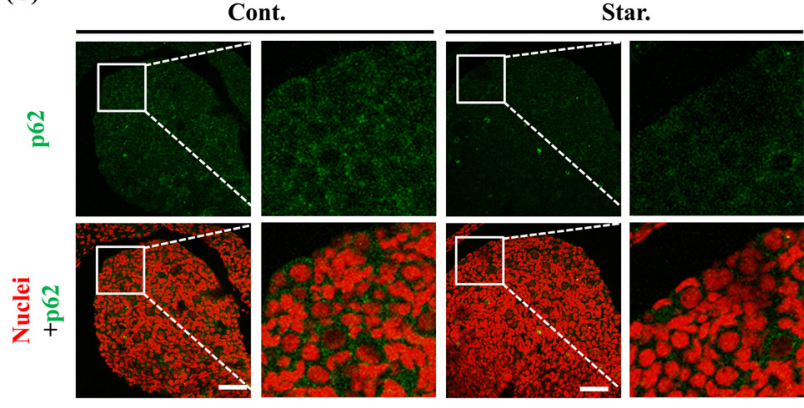

Fig. 4. (A) Protein expression of the selective autophagy substrate p62 in ovaries from control and starved groups at $12-36 \mathrm{~h}$ after birth. (B) Relative levels of expression of p62 are shown in bar graphs. GAPDH was used as a loading control. Each bar is expressed as the mean $\pm \mathrm{SE}(\mathrm{n}=7)$. An asterisk indicates a significant difference $(\mathrm{P}<0.05)$. p62 decreased in the starved group compared with the control group at $36 \mathrm{~h}$. (C) Fluorescent images from immunostaining of the $\mathrm{p} 62$ protein in ovaries from control and starved groups at $36 \mathrm{~h}$ after birth. Scale bar $=50 \mu \mathrm{m}$. The photographs on the right side of each experimental group are the quadruple enlargement of the white frame from images on the left. The signals of p62 were detected in the cytoplasm of oocytes.

decreasing to the basal level in about $24 \mathrm{~h}$ [9]. In this study, the neonatal mice were fed by nursing 1 to $2 \mathrm{~h}$ after birth, which is before the maximum point of autophagy activity. Another study also reported a strong immune signal of LAMP-1 in PFs in the spiny mouse, including a significant increase in Lamp-1 expression 1 day after birth and lysosomal amplification [10]. Importantly, it has also been reported in several studies that the absence of autophagy leads to an excessive loss of ovarian PFs in neonatal mice. Recent studies reported that a reduction of germ cells was found in Becn1-deficient ovaries [8]. It has also been reported that germ cell-specific Atg7 knockout leads to loss of PFs in 3-day-old mice [9].

Our results showed that the expression of autophagy markers was localized to oocytes and the expression was increased due to starvation, indicating that autophagy is induced in neonatal mouse ovaries. Hence, we propose that this autophagy induction is involved in the transition from oocytes to PFs and the number of PFs that are formed. The effects of starvation on the number of PFs at different points in the perinatal period have been reported in previous studies $[23,34]$. Maternal nutritional restriction can result in offspring with reduced ovarian stockpiles and early ovarian aging [23]. Another study reported that the number of oocytes and follicles of 3-day-old mice in which lactation was restricted for $20 \mathrm{~h}$ immediately after birth was lower than those in normal mice [9]. In above report, autophagy activity in starved mice was not investigated. In our
(A)

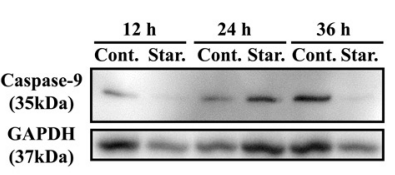

(C)

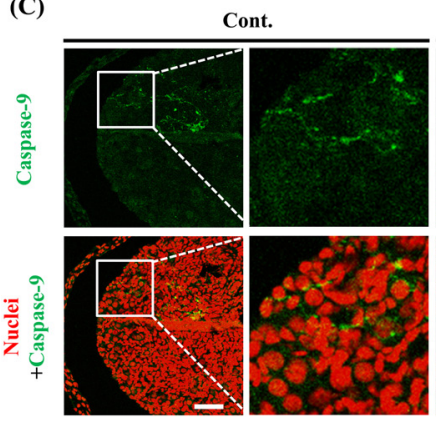

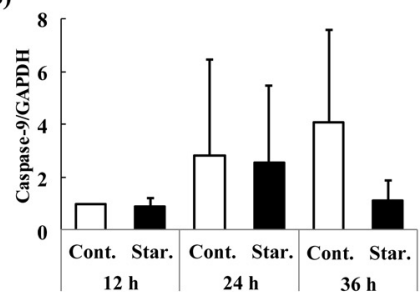

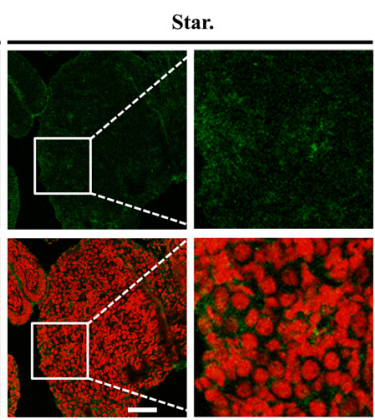

Fig. 5. (A) Protein expression of the apoptosis marker caspase-9 in ovaries from control and starved groups at 12 to $36 \mathrm{~h}$ after birth. (B) Relative expression levels of caspase- 9 are shown in bar graphs. GAPDH was used as a loading control. Each bar is expressed as the mean $\pm \mathrm{SE}(\mathrm{n}=4)$. Caspase-9 levels were decreased in the starved group compared with the control group at $36 \mathrm{~h}$. (C) Fluorescent images from immunostaining of the caspase- 9 protein in ovaries from control and starved groups at 36 $\mathrm{h}$ after birth. Scale bar $=50 \mu \mathrm{m}$. The photographs on the right side of each experimental group are the quadruple enlargement of the white frame from images on the left. Caspase- 9 was localized in the cytoplasm of both oocytes and somatic cells.

study, the possibility cannot be ruled out that the significant increase in the number of PFs at $36 \mathrm{~h}$ by starvation might be temporary. However, of the observed increase in autophagy-related proteins and apoptosis marker proteins suggest that the increase in PF number at $36 \mathrm{~h}$ can be attributed to the continuous induction of higher levels of autophagy over the $24 \mathrm{~h}$ after birth. In contrast to our results, in CD1 mice that were starved between Day 1.5 and 3 post-partum, the number of PFs per section was decreased [34]. This may be due to differences in mouse strain. Alternatively, the difference may be due to the difference in timing of starvation relative to the peak of PF formation. PF numbers peaked around $60 \mathrm{~h}$ after birth in our study. Therefore, we performed starvation during the increasing phase of PFs, earlier than the previous study. Thus, influences on the number of PFs may be changed if starvation is performed before the peak of PF formation or during the decreasing phase.

Apoptosis is thought to be the major mechanism for germ cell attrition during fetal development $[23,35,36]$, massive oocyte nest breakdown $[13,34]$, and granulosa cell death during postnatal life [12, $13,23]$. In this study, to investigate the issue of whether autophagy mainly contributes to cell survival or apoptosis, caspase-3, which has an important role in apoptosis in the ovary, and caspase- 9 , which induces it, were examined. The expression of caspase- 9 tended to be suppressed by starvation, but the expression of caspase- 3 could not be detected, regardless of starvation and the frequency of apoptosis 
in the neonatal stage ovaries. These results are consistent with the lack of TUNEL response, positive staining for an apoptosis marker, and expression in rodent and human PFs.

In a previous study, $\operatorname{Atg} 7$ knockout mice were found to have significantly fewer offspring and to develop infertility at 6 months of age after the 2nd generation [9]. In addition, aged $\operatorname{Atg} 7$ knockout mice have very few PFs and most of the mice are almost completely infertile. We have not confirmed whether there is an effect on reproductive ability after starved neonatal mice reached maturity because these starved mice were sacrificed, even when they were returned to their mothers after suckling restriction. Therefore, it is unclear whether an increase in the number of PFs during the newborn period is maintained and influences reproductive performance.

In conclusion, our study indicates that non-suckling starvation immediately after birth promotes PF formation with concomitant autophagy activation, suggesting that autophagy may accelerate differentiation or the formation of PFs from naked oocytes. In a future study, we plan to verify whether the administration of an autophagy inducer to neonatal mice upregulates the number of PFs, and whether this affects reproductive ability.

\section{Acknowledgments}

This work was supported by the MEXT Program for supporting research activities of female researchers and by JSPS KAKENHI Grant Number 17J02206.

\section{References}

1. Pepling ME. From primordial germ cell to primordial follicle: mammalian female germ cell development. Genesis 2006; 44: 622-632. [Medline] [CrossRef]

2. Rüsse I. Oogenesis in cattle and sheep. Bibl Anat 1983; 24: 77-92. [Medline]

3. Maheshwari A, Fowler PA. Primordial follicular assembly in humansrevisited. Zygote 2008; 16: 285-296. [Medline] [CrossRef]

4. Edinger AL, Thompson CB. Death by design: apoptosis, necrosis and autophagy. Curr Opin Cell Biol 2004; 16: 663-669. [Medline] [CrossRef]

5. Klionsky DJ, Emr SD. Autophagy as a regulated pathway of cellular degradation. Science 2000; 290: 1717-1721. [Medline] [CrossRef]

6. Mizushima N, Ohsumi Y, Yoshimori T. Autophagosome formation in mammalian cells. Cell Struct Funct 2002; 27: 421-429. [Medline] [CrossRef]

7. Barth JM, Szabad J, Hafen E, Köhler K. Autophagy in Drosophila ovaries is induced by starvation and is required for oogenesis. Cell Death Differ 2011; 18: 915-924. [Medline] [CrossRef]

8. Gawriluk TR, Hale AN, Flaws JA, Dillon CP, Green DR, Rucker EB 3rd. Autophagy is a cell survival program for female germ cells in the murine ovary. Reproduction 2011; 141: 759-765. [Medline] [CrossRef]

9. Song ZH, Yu HY, Wang P, Mao GK, Liu WX, Li MN, Wang HN, Shang YL, Liu C, Xu ZL, Sun QY, Li W. Germ cell-specific Atg7 knockout results in primary ovarian insufficiency in female mice. Cell Death Dis 2015; 6: e1589. [Medline] [CrossRef]

10. Hulas-Stasiak M, Gawron A. Follicular atresia in the prepubertal spiny mouse (Acomys cahirinus) ovary. Apoptosis 2011; 16: 967-975. [Medline] [CrossRef]

11. Adhikari D, Flohr G, Gorre N, Shen Y, Yang H, Lundin E, Lan Z, Gambello MJ, Liu K. Disruption of Tsc2 in oocytes leads to overactivation of the entire pool of primordial follicles. Mol Hum Reprod 2009; 15: 765-770. [Medline] [CrossRef]

12. Adhikari D, Zheng W, Shen Y, Gorre N, Hämäläinen T, Cooney AJ, Huhtaniemi I, Lan ZJ, Liu K. Tsc/mTORC1 signaling in oocytes governs the quiescence and activation of primordial follicles. Hum Mol Genet 2010; 19: 397-410. [Medline] [CrossRef]

13. Reddy P, Liu L, Adhikari D, Jagarlamudi K, Rajareddy S, Shen Y, Du C, Tang W,
Hämäläinen T, Peng SL, Lan ZJ, Cooney AJ, Huhtaniemi I, Liu K. Oocyte-specific deletion of Pten causes premature activation of the primordial follicle pool. Science 2008; 319: 611-613. [Medline] [CrossRef]

14. Wang N, Luo LL, Xu JJ, Xu MY, Zhang XM, Zhou XL, Liu WJ, Fu YC. Obesity accelerates ovarian follicle development and follicle loss in rats. Metabolism 2014; 63 94-103. [Medline] [CrossRef]

15. Liu WJ, Zhang XM, Wang N, Zhou XL, Fu YC, Luo LL. Calorie restriction inhibit ovarian follicle development and follicle loss through activating SIRT1 signaling in mice. Eur J Med Res 2015; 20: 22. [Medline] [CrossRef]

16. Zheng X, Li Y, Zhao R, Yan F, Ma Y, Zhao L, Qiao H. xCT deficiency induces autophagy via endoplasmic reticulum stress activated $\mathrm{p} 38$-mitogen-activated protein kinase and mTOR in sut melanocytes. Eur J Cell Biol 2016; 95: 175-181. [Medline] [CrossRef]

17. Pedersen T, Peters H. Proposal for a classification of oocytes and follicles in the mouse ovary. J Reprod Fertil 1968; 17: 555-557. [Medline] [CrossRef]

18. Bernal AB, Vickers MH, Hampton MB, Poynton RA, Sloboda DM. Maternal undernutrition significantly impacts ovarian follicle number and increases ovarian oxidative stress in adult rat offspring. PLoS ONE 2010; 5: e15558. [Medline] [CrossRef]

19. Kabeya Y, Mizushima N, Ueno T, Yamamoto A, Kirisako T, Noda T, Kominami E, Ohsumi Y, Yoshimori T. LC3, a mammalian homologue of yeast Apg8p, is localized in autophagosome membranes after processing. EMBO J 2000; 19: 5720-5728. [Medline] [CrossRef]

20. Fukuda M. Lysosomal membrane glycoproteins. Structure, biosynthesis, and intracellular trafficking. J Biol Chem 1991; 266: 21327-21330. [Medline]

21. Fujiwara Y, Komiya T, Kawabata H, Sato M, Fujimoto H, Furusawa M, Noce T. Isolation of a DEAD-family protein gene that encodes a murine homolog of Drosophila vasa and its specific expression in germ cell lineage. Proc Natl Acad Sci USA 1994; 91: 12258-12262. [Medline] [CrossRef]

22. Ichimura Y, Kominami E, Tanaka K, Komatsu M. Selective turnover of p62/A170 SQSTM1 by autophagy. Autophagy 2008; 4: 1063-1066. [Medline] [CrossRef]

23. Bjørkøy G, Lamark T, Brech A, Outzen H, Perander M, Overvatn A, Stenmark H, Johansen T. p62/SQSTM1 forms protein aggregates degraded by autophagy and has a protective effect on huntingtin-induced cell death. J Cell Biol 2005; 171: 603-614. [Medline] [CrossRef]

24. Kuma A, Hatano M, Matsui M, Yamamoto A, Nakaya H, Yoshimori T, Ohsumi Y, Tokuhisa T, Mizushima N. The role of autophagy during the early neonatal starvation period. Nature 2004; 432: 1032-1036. [Medline] [CrossRef]

25. Yu L, Lenardo MJ, Baehrecke EH. Autophagy and caspases: a new cell death program. Cell Cycle 2004; 3: 1124-1126. [Medline] [CrossRef]

26. Lum JJ, DeBerardinis RJ, Thompson CB. Autophagy in metazoans: cell survival in the land of plenty. Nat Rev Mol Cell Biol 2005; 6: 439-448. [Medline] [CrossRef]

27. Mizushima N, Levine B. Autophagy in mammalian development and differentiation. Nat Cell Biol 2010; 12: 823-830. [Medline] [CrossRef]

28. Mizushima N, Komatsu M. Autophagy: renovation of cells and tissues. Cell 2011; 147: 728-741. [Medline] [CrossRef]

29. Qu X, Zou Z, Sun Q, Luby-Phelps K, Cheng P, Hogan RN, Gilpin C, Levine B. Autophagy gene-dependent clearance of apoptotic cells during embryonic development. Cell 2007; 128: 931-946. [Medline] [CrossRef]

30. Meijer AJ, Codogno P. Regulation and role of autophagy in mammalian cells. Int $J$ Biochem Cell Biol 2004; 36: 2445-2462. [Medline] [CrossRef]

31. Wang H, Wan H, Li X, Liu W, Chen Q, Wang Y, Yang L, Tang H, Zhang X, Duan E, Zhao X, Gao F, Li W. Atg7 is required for acrosome biogenesis during spermatogenesis in mice. Cell Res 2014; 24: 852-869. [Medline] [CrossRef]

32. Gozuacik D, Kimchi A. Autophagy as a cell death and tumor suppressor mechanism. Oncogene 2004; 23: 2891-2906. [Medline] [CrossRef]

33. Komatsu M, Waguri S, Ueno T, Iwata J, Murata S, Tanida I, Ezaki J, Mizushima N, Ohsumi Y, Uchiyama Y, Kominami E, Tanaka K, Chiba T. Impairment of starvationinduced and constitutive autophagy in Atg7-deficient mice. J Cell Biol 2005; 169: 425-434. [Medline] [CrossRef]

34. Wang YY, Sun YC, Sun XF, Cheng SF, Li B, Zhang XF, De Felici M, Shen W. Starvation at birth impairs germ cell cyst breakdown and increases autophagy and apoptosis in mouse oocytes. Cell Death Dis 2017; 8: e2613. [Medline] [CrossRef]

35. Hurst PR, Mora JM, Fenwick MA. Caspase-3, TUNEL and ultrastructural studies of small follicles in adult human ovarian biopsies. Hum Reprod 2006; 21: 1974-1980. [Medline] [CrossRef]

36. Tingen CM, Bristol-Gould SK, Kiesewetter SE, Wellington JT, Shea L, Woodruf TK. Prepubertal primordial follicle loss in mice is not due to classical apoptotic pathways. Biol Reprod 2009; 81: 16-25. [Medline] [CrossRef] 